\title{
The Impact of a Pandemic COVID-19 on the Incidence of Borreliosis in Poland
}

\author{
Mariusz Piotrowski ${ }^{1}$ [D $\cdot$ Anna Rymaszewska ${ }^{1}$
}

Received: 6 June 2021 / Accepted: 9 November 2021 / Published online: 3 January 2022

(c) The Author(s) 2022

\begin{abstract}
Purpose Lyme disease is the most common tick-borne disease, caused by spirochetes of the genus Borrelia, transmitted by ticks of the Ixodes genus in Poland. The purpose of this analysis was whether the COVID-19 outbreak had a significant impact on the number of reported Lyme disease cases.

Materials and Methods The data included in the World Health Organization (WHO) and the data from the "Reports on incidence of infectious diseases, infections and poisoning in Poland" presented by the Department of Epidemiology NIZPPZH were analyzed.

Results To the end of 2020, there were registered 12, 524 Lyme disease cases. In the same period, in 2018 and 2019 were registered, respectively, 20, 150 and 20, 614 Lyme disease cases. The overall number of Lyme disease cases in 2018 and 2019 was at a similar level. The monthly increase in the number of cases was also at a similar level. The year 2020 in January and February was characterized by the same increase in the number of cases as in previous years. The difference started to be noticeable in March and the lowered growth compared to the previous years has been maintained to this day. In December, about 8, 000 fewer cases of Lyme disease were registered than in previous years.

Conclusion The reduced number of cases of Lyme disease coincided with the beginning of the COVID-19 epidemic in Poland in March 2020. Every year, the incidence of Lyme disease in Poland is at a similar level with a similar monthly increase. The outbreak of the COVID-19 pandemic had a significant impact on the number of cases recorded, which could have catastrophic consequences for people who did not receive treatment in the right time.
\end{abstract}

Keywords Borreliosis · Lyme disease · Poland · COVID-19 · SARS-CoV-2

\section{Introduction}

The novel coronavirus disease (COVID-19), induced by severe acute respiratory syndrome coronavirus 2 (SARSCoV-2) and first reported in late December 2019 in Wuhan, China, quickly became an emerging, rapidly evolving situation, spreading inevitably outside China and the Asian continent, and it was declared a pandemic in March 2020 [1], 2. Under these circumstances, different countries confirming their first cases began to implement a strict hygiene regime and eventually imposed city-wide and national lockdown

Mariusz Piotrowski

mariusz.piotrowski@bio-space.pl

Anna Rymaszewska

anna.rymaszewska@usz.edu.pl

1 Institute of Biology, University of Szczecin,

70-453 Szczecin, Poland measures. As a result, an estimated 4 billion people were forced to quarantine themselves at home. According to data from the World Health Organization (WHO), the coronavirus disease (COVID-19) has spread to almost all countries around the world. As of 10 January 2021, the number of confirmed cases was $88,383,771$ and the number of deaths was $1,919,126$ [6].

The current goal of governments and ministries of health is to implement urgent measures to minimize the number of people infected with SARS-CoV-2. While it is of utmost importance to focus on controlling this communicable disease, a pandemic could also have long-term effects on people with non-communicable diseases.

Although there is no peer-reviewed scientific evidence on this issue yet, initial reports from scientific societies in Italy and Spain suggest a substantial reduction in admission for stroke or Myocardial infarction since the start of the outbreak, for example. In Spain, cardiologists have seen 
a $40 \%$ reduction in heart attack treatments and a decrease in the number of diagnostic procedures. One hypothesis is that individuals do not go to the hospital even if they need to. There is also a shortage of healthcare staff to cover both SARS-CoV-2-related illness and all other routine medical care [3].

In Poland, one of the non-communicable diseases that affects 20,000 people every year is Lyme disease, which is a mandatorily notifiable disease entity, therefore precise data are available [4]. Lyme disease, known also as borreliosis is caused by spirochaetes belonging to the Borrelia burgdorferi sensu lato complex, carried by Ixodes ticks. B. burgdorferi is one of the most significant human pathogens transmitted by ticks [5].

\section{Epidemiological Situation of Lyme Disease in Poland After the Start of the COVID-19 Epidemic in 2020}

The epidemiological situation of Lyme disease in Poland based on the data from the "Reports on incidence of infectious diseases, infections and poisoning in Poland" presented by the Department of Epidemiology NIZP-PZH.

To the end of 2020, there were registered 12,524 Lyme disease cases. In the same period, in 2018 and 2019, were registered, respectively, 20,150 and 20,614 Lyme disease cases. Incidence rate in 2020 in Poland was 32,63 per 100,000 population and it was much lower, i.e., by 19,83 and 21,03 in comparison to the incidence rate in 2018 and 2019, respectively (Table 1).

The overall number of Lyme disease cases in 2018 and 2019 was at a similar level. The monthly increase in the number of cases was also at a similar level. The year 2020 in January and February was characterized by the same increase in the number of cases as in previous years. The difference started to be noticeable in March and the lowered growth compared to the previous years has been maintained to this day. In December, about 8000 fewer cases of Lyme disease were registered than in previous years. The reduced number of cases of Lyme disease coincided with the beginning of the COVID-19 epidemic in Poland in March 2020 (Fig. 1).

\section{Summary and conclusion}

The first case of COVID-19 in Poland was confirmed on 4 March 2020. School and university closure was imposed on 11 March; on 15 March, borders were closed to foreigners; from 24 March, a nationwide lockdown was imposed; on 20 April, the ban on the recreational use of forests and parks was lifted; on 4 May, hotels and shopping centers were permitted to reopen; and since 6 May, daycare centers and kindergartens have been allowed to welcome their pupils again. In other words, for the majority of Poles, the stay-at-home order encompassed six weeks. The on-going pandemic (COVID-19), caused by the coronavirus SARS-CoV-2, has dramatically impacted on people from public health. One consequence of quarantine measures was a decrease in physical activity levels in many individuals. In addition to laws limiting access to outdoor space. During the SARS-CoV-2 outbreak, healthcare systems began postponing and scaling down some aspects of routine management, outpatient visits, and non-urgent surgery to avoid unnecessary hospital visits, reduce the burden on hospitals, and decrease infection risk. Although there are no data available yet on this issue, it is likely that many patients have decreased access to outpatient visits and one-on-one clinical advice,
Table 1 Increase in the incidence of Lyme disease in Poland in 2018, 2019 and 2020. Number of cases and incidence per 100,000 population

\begin{tabular}{|c|c|c|c|c|c|c|}
\hline & \multicolumn{2}{|l|}{2018} & \multicolumn{2}{|l|}{2019} & \multicolumn{2}{|l|}{2020} \\
\hline & No of cases & $\begin{array}{l}\text { Inci- } \\
\text { dence/100,000 }\end{array}$ & No of cases & $\begin{array}{l}\text { Inci- } \\
\text { dence } / 100,000\end{array}$ & No of cases & $\begin{array}{l}\text { Inci- } \\
\text { dence/100,000 }\end{array}$ \\
\hline January & 1118 & 2,91 & 916 & 2,39 & 913 & 2,38 \\
\hline February & 2172 & 5,65 & 1934 & 5,04 & 1934 & 5,04 \\
\hline March & 3261 & 8,49 & 2954 & 7,70 & 2257 & 5,88 \\
\hline April & 4232 & 11,02 & 3809 & 9,92 & 2509 & 6,54 \\
\hline May & 5485 & 14,28 & 4964 & 12,93 & 2985 & 7,78 \\
\hline June & 7349 & 19,13 & 6685 & 17,41 & 4259 & 11,10 \\
\hline July & 9757 & 25,40 & 9333 & 24,31 & 6435 & 16,76 \\
\hline August & 12586 & 32,76 & 11876 & 30,94 & 7847 & 20,44 \\
\hline September & 14762 & 38,43 & 14288 & 37,22 & 9376 & 24,43 \\
\hline October & 17049 & 44,38 & 16788 & 43,70 & 9857 & 25,68 \\
\hline November & 18753 & 48,82 & 19020 & 49,51 & 10710 & 27,90 \\
\hline December & 20150 & 52,46 & 20614 & 53,66 & 12524 & 32,63 \\
\hline
\end{tabular}




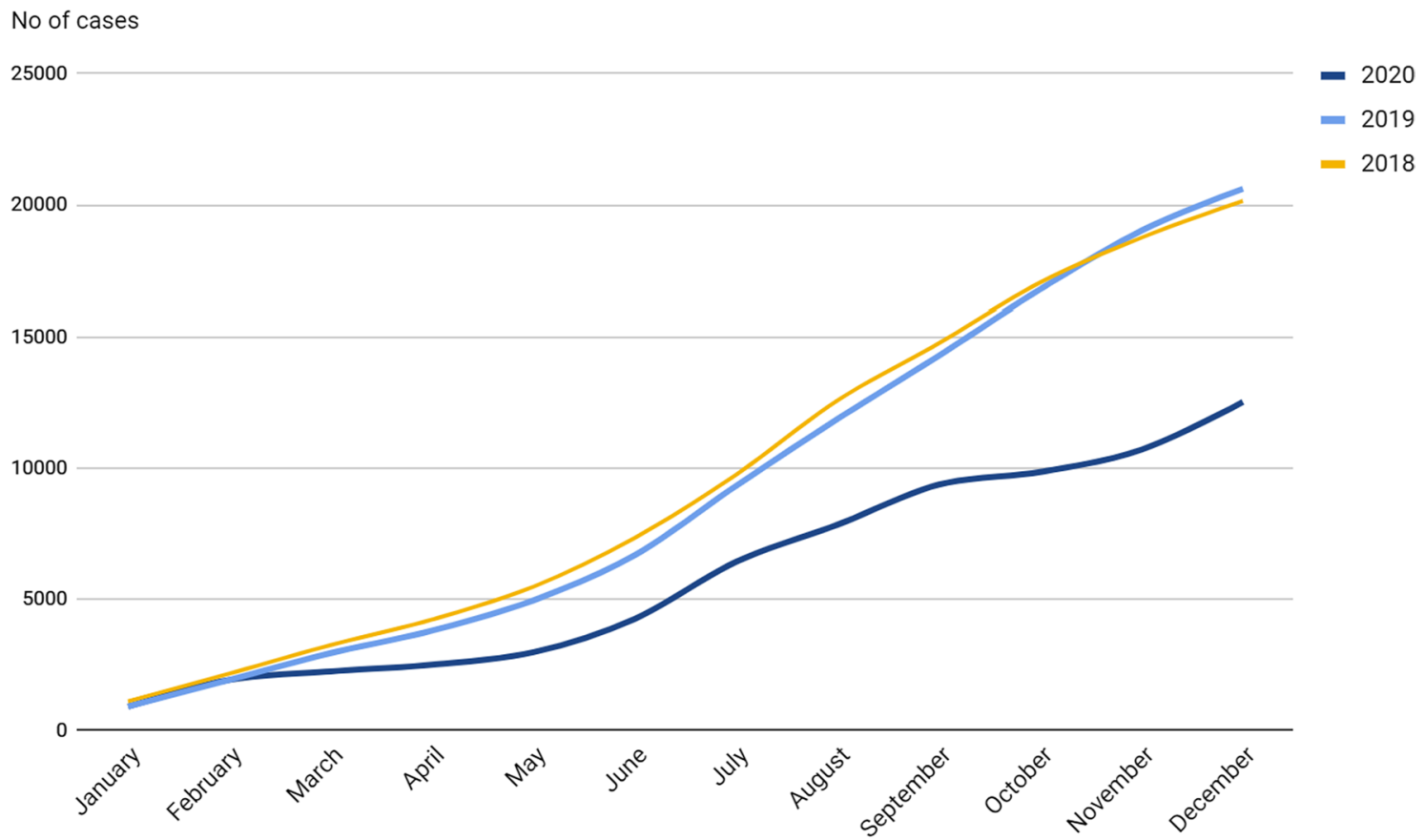

Fig. 1 Monthly increase in the incidence of Lyme disease in 2018, 2019 and 2020

and in some cases, there may be a shortage of medicines. Further, some patients may be reluctant to seek care due to fears of infection in healthcare settings. The situation is further exacerbated by the preexisting European shortage of skilled healthcare workers and that many healthcare workers have been infected with SARS-CoV-2, which affects staffing levels.

The above situation is very well illustrated in the example of Lyme disease in Poland. Every year, the incidence of Lyme disease in Poland is at a similar level with a similar monthly increase. The outbreak of the COVID-19 pandemic had a significant impact on the number of cases recorded, which could have catastrophic consequences for people who did not receive treatment in the right time.

Open Access This article is licensed under a Creative Commons Attribution 4.0 International License, which permits use, sharing, adaptation, distribution and reproduction in any medium or format, as long as you give appropriate credit to the original author(s) and the source, provide a link to the Creative Commons licence, and indicate if changes were made. The images or other third party material in this article are included in the article's Creative Commons licence, unless indicated otherwise in a credit line to the material. If material is not included in the article's Creative Commons licence and your intended use is not permitted by statutory regulation or exceeds the permitted use, you will need to obtain permission directly from the copyright holder. To view a copy of this licence, visit http://creativecommons.org/licenses/by/4.0/.

\section{References}

1. Cucinotta D, Vanelli M (2020) WHO declares COVID-19 a pandemic. Acta Bio Med 91:157-160. https://doi.org/10.23750/abm. v91i1.9397

2. Jiang S, Xia S, Ying T, Lu L (2020) A novel coronavirus (2019$\mathrm{nCoV}$ ) causing pneumonia-associated respiratory syndrome. Cell Mol Immunol 17:554. https://doi.org/10.1038/s41423-020-0372-4

3. Palmer K, Monaco A, Kivipelto M, Onder G, Maggi S, Michel JP, Prieto R, Sykara G, Donde S (2020) The potential long-term impact of the COVID-19 outbreak on patients with non-communicable diseases in Europe: consequences for healthy ageing. Aging Clin Exp Res 32(7):1189-1194. https://doi.org/10.1007/ s40520-020-01601-4

4. Polish National Institute of Hygiene (http://www.pzh.gov.pl).

5. Wodecka B, Leońska A, Skotarczak B (2010) A comparative analysis of molecular markers for the detection and identification of Borrelia spirochaetes in Ixodes ricinus. J Med Microbiol 59:309-314. https://doi.org/10.1099/jmm.0.013508-0

6. World Health Organization (WHO) (2021). Coronavirus disease (COVID-19) pandemic. (https://covid19.who.int/)

Publisher's Note Springer Nature remains neutral with regard to jurisdictional claims in published maps and institutional affiliations. 